\title{
Storage and Management for Medicines in the Home of University Students of the Health Area of Espoch, Ecuador
}

\author{
John Ortiz-Simbaña ${ }^{1,3}$, Paola Villalón-Muñoz ${ }^{1,2}$, Elizabeth Escudero-Vilema ${ }^{1}$, Sandy Toapanta-Rivera ${ }^{1,4}$ and \\ Adriana Rincón-Alarcón ${ }^{1}$ \\ 1. Research Group in Technology and Pharmaceutical Care of Ecuador (GITAFEC), Polytechnic Higher School of Chimborazo, \\ Faculty of Sciences, Riobamba CP 060150, Ecuador \\ 2. Life Sciences Department, Amazon State University, Puyo CP 160150, Ecuador \\ 3. Department of Productive Development, GAD of the Province of Morona Santiago, Macas CP 140150, Ecuador \\ 4. Pharmacy Department, Santa Inés Hospital, Tungurahua CP 180150, Ecuador
}

\begin{abstract}
This work collects the characteristics of the family kits of students from the careers related to health in the Espoch, by identifying their knowledge and habits to determine the relationship between self-medication and the possession of medicines contained in the first-aid kit. This is related to the most outstanding frequency (48.1\% bedroom) with the use of medicines in the home (48.5\% when the treatment ends). Taking into account that $63.6 \%$ do not have a kit, they stored them in inadequate places to control their stability and quality for the use they were made, being analgesics and antibiotics those commonly found during the inspection that took place in the home. This determines that storage habits are not adequate for the proper storage of medications, including having knowledge of health and the importance of proper use by students, being essential to know that medicines must be stored in fresh places and dry, to avoid damage and problems associated with its stability.
\end{abstract}

Key words: First-aid kit, self-medication, university students, storage of medicines, Riobamba (canton), biochemistry and pharmacy.

\section{Introduction}

The quality, safety and efficacy of medicines are essential factors to meet the therapeutic objectives set by the prescriber, and will depend not only on the manufacturing process, but on the proper preservation in which they are stored [1], therefore, it is fundamental that the stability characteristics that allowed the allocation of a useful life period will be maintained, requiring that during the storage of medicines in the home people take decisive parameters in the stability of these. These aspects should be taken into account temperature, humidity and light, since all these factors accelerate the process of decomposition of drugs, resulting in a decrease in the therapeutic action that is

Corresponding author: Adriana Rincón, Ph.D., professor, research fields: pharmacy, care and pharmaceutical technology. required [2, 3]. In the same way, it is important to consider the expiration date of the products, which is included in all the packages of the medicines [4] and which guarantee that until the indicated date the physical, chemical, microbiological and toxicological characteristics within the limits, which are valid if they are stored in conditions of adequate light, temperature and humidity and established by the manufacturer. [5]

In others studies, it has been found that the storage conditions of medicines in homes are inadequate, since many of them are kept in the kitchen, bathroom or rooms; in addition, recommendations such as the revision of expiration dates, the avoidance of self-medication or the recommendations of the labels are ignored [6]. In a study conducted on the analysis of the use of medications in older adults in Costa Rica [7], erroneous conservation practices of certain drugs were 
found, such as insulin that was placed in the refrigerator door, being exposed to variations in temperatures that could affect the stability of the active principle; in addition, the persistence of the practice of storage in the kitchen was detected and within the reach of children, which generated active intervention with the recommendations and necessary adjustments, in order to reduce the risks and improve storage practices in the home. [8]

The proper storage of medicines, as well as their proper preservation both in the health center, pharmacy and at home are essential to ensure that they do not lose their quality and continue to be effective when used by the population that needs them $[9,10]$, which is why its proper place of storage in the home is the family kit, located out of the reach of children and placed like kitchens, bathrooms that are sources of heat and humidity. Similarly, World Health Organization (WHO) recommends reviewing family kits at least twice a year, to have control over those products that are expired or in poor condition, which may not be suitable for consumption, preventing them from becoming a storage place of medicines in disuse or obsolete, which adversely affects health. [11]

The practice of dispensing medicines in a pharmaceutical service is to provide users with timely information about their handling and storage, so that these stored substances do not suffer degradation, contamination, loss of active principles or effectiveness and avoid confusion or intoxication, when they are used in homes [12, 13].

In accordance with the above, this study was conducted in order to analyze the storage conditions of medicines in the home and the good practices of the medicines in relation to their use by students, taking into account that these belong to the area of health and that they should have knowledge about good storage and utilization practices, as well as the risks that may occur due to their bad practice. [14]

\section{Materials and methods}

\subsection{Materials}

The type of study was observational, descriptive, cross-sectional and non-probabilistic, proposing a mixed approach, seeking to analyze the knowledge and practices on the storage and handling of medications, considering the characteristics of the family medicine kit that students in the area have in their homes of the health of the Espoch, participants in the study. Data collection was carried out in 440 individuals, divided into 110 students from each career who agreed to participate voluntarily in the delivery of data. An experimental group was considered in the research, selected for its direct relationship with health and drugs, formed by medicine, biochemistry and pharmacy and the career of promotion and health care. The control group was constituted by the career in maintenance engineering, selected at random among the careers in the field of engineering, industry and construction.

\subsection{Methods}

In the first stage the data were collected through surveys (Figure 1) and based on the authorizations granted, the visit was made to 22 homes of students in the city of Riobamba, through the checklist a qualitative and quantitative observation of the medicines present in the home.

\subsection{Statistic Analysis}

The information collected and systematized was analyzed using Excel, SPSS v.22 and SPAD v.5.6.

\section{Results}

About the presence of first-aid kits in the homes of the respondents, it was found that $49.5 \%$ said they possess a medicine cabinet, this value corresponding to students in the careers of biochemistry and pharmacy 


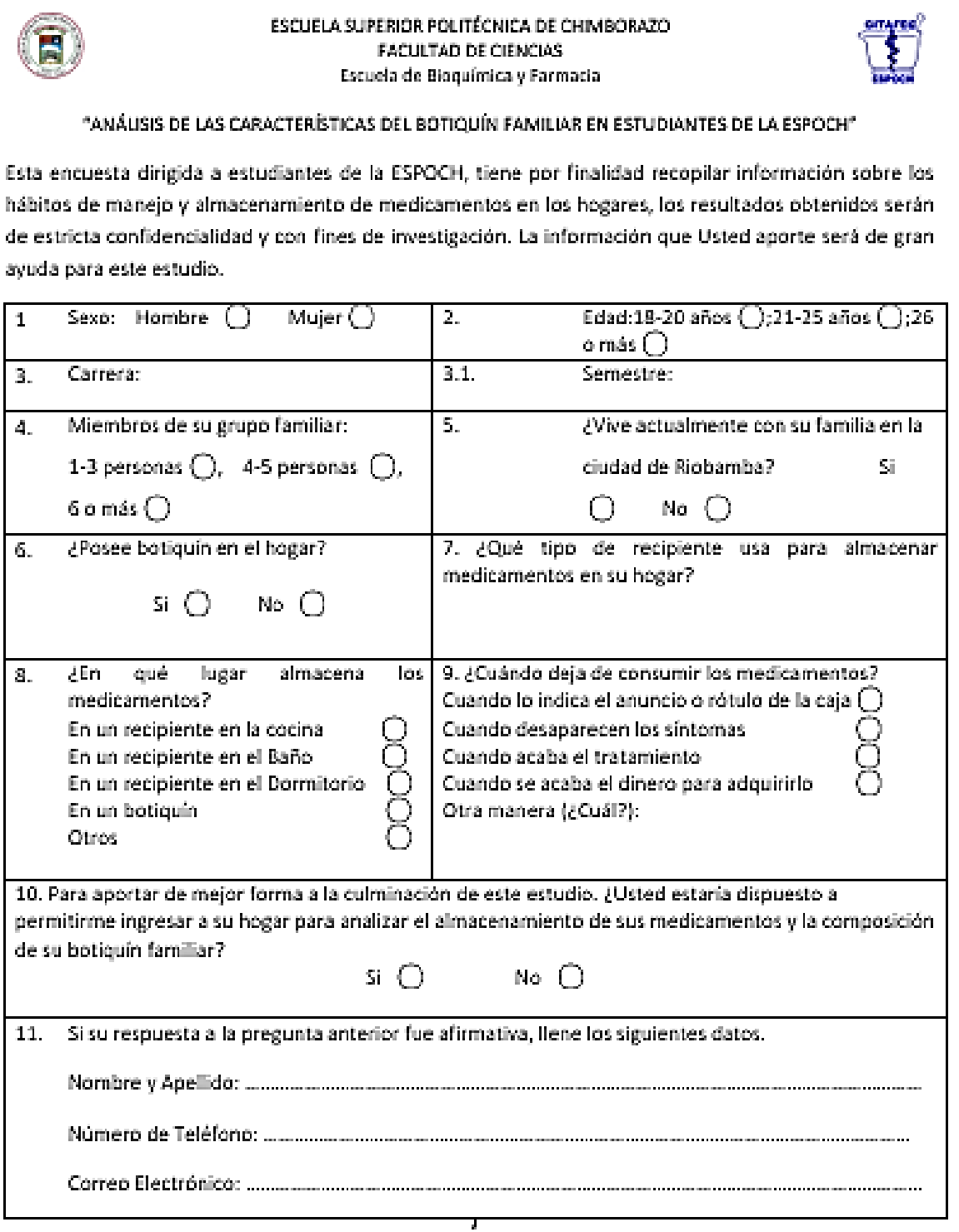

Fig. 1 Survey model applied to students participating in the research

and maintenance engineering; while $49.3 \%$ of the students who answered not having a kit, belonged to the careers of medicine and promotion and health care. It is evident that the percentages of students who had a first aid kit in their home with respect to those who did not possess it, were equitable and had no direct relationship with the area to which the career they study belongs.

The results showed that in a general way, $48.1 \%$ of the respondents had medicines kept in the bedroom and within the reach of the children, $7.1 \%$ kept them in the kitchen and 5.1\% assured to store them in the bathroom exposing them to conditions of humidity and heat, so that approximately $60.3 \%$ carried out improper storage practices, against $27.1 \%$ of students who exhibited storing them in a first-aid kit and $8.0 \%$ collected them in other places as the room or study, as shown in Fig. 2.

When applying the correspondence analysis test between the variables between sex, race and place of storage to determine the habits of the students with respect to the medications, it was observed that those belonged to the career in maintenance engineering, being conformed in its great majority by men and being the control group of the present study, they accumulate 


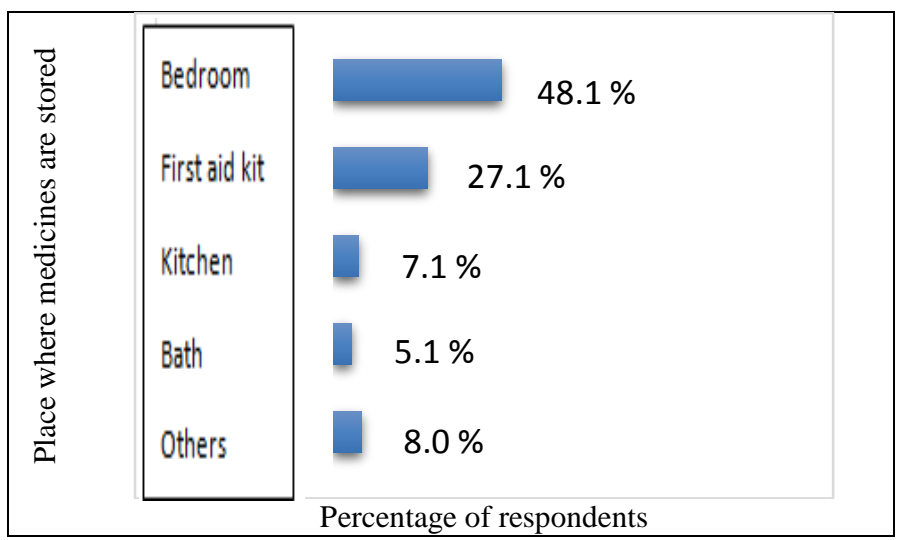

Fig. 2 Place of storage of medicines.

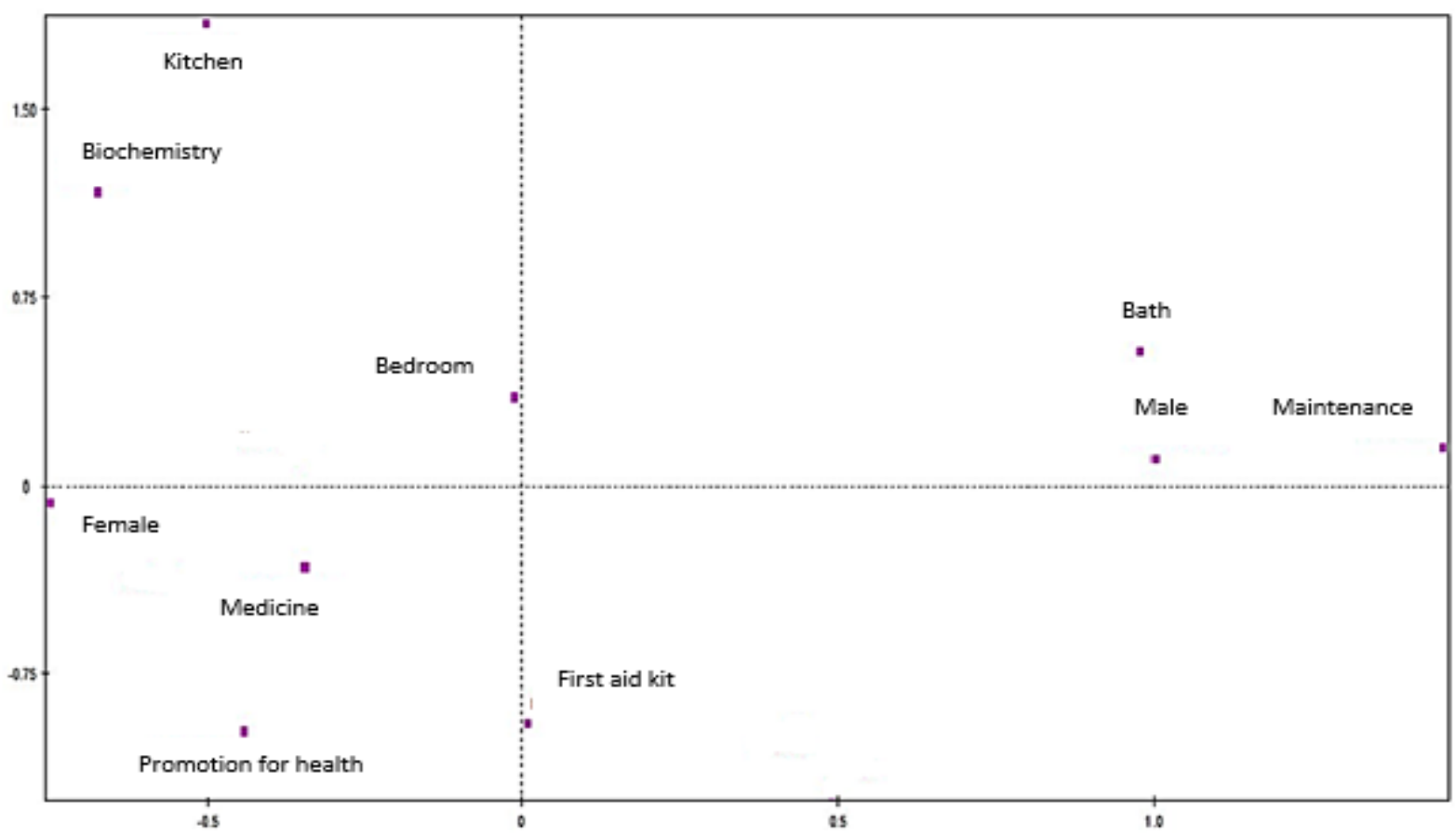

Fig. 3 Relationship between place of storage, areas of health and sex.

medicines in the bathroom, possibly by the fact that these do not receive in their career knowledge about their correct storage. With respect to the students that belong to the health area, both biochemistry and pharmacy, degree in promotion and care for health and medicine, which are mostly represented by women, have similar habits to those of the control group, because they keep the medicines in inadequate places like the kitchen, where an environment of humidity and temperature does not favor the stability of them. For this reason, good storage practices are not determined, regardless of the type of career the students take, as shown in Fig. 3.

These results are comparable with those obtained in a research carried out at the University of Granada. The students of the pharmacy degree did not have a clear idea about the optimal storage place of the medicines, since most of them (63\%) kept them in inadequate places like the kitchen (44\%) or the bathroom (27\%) $[15,16]$. Similar results were obtained with nursing students where 31.9\% kept them in the kitchen, 39.9\% in the bathroom, $11.6 \%$ in the bedroom and $16.7 \%$ in other places such as dining room or hallway, being the bathroom where they stored most often. In addition, it 
can be assured that the storage practices reported by the students are not the best even though they receive adequate training on the subject $[17,18]$.

It was also found that approximately half (48.5\%) of the students surveyed said that they stopped using the drugs when the treatment prescribed by the doctor ended, however, the majority percentage was formed for reasons that are negative for health and oriented towards the practice of self-medication, because the drugs were not administered using the criterion considered by the patient, as shown in Fig. 3. These attitudes that respondents claim to have, with respect to the causes that drive the cessation of drug use in many cases allow their storage in the home. The results is in
Fig. 4.

During the evaluation of the attitudes on the storage and handling of medicines in the home, consent was obtained for the revision of the kit in 22 homes, finding that $63.6 \%$ (14 households) did not have a kit as such, but stored medicines in cardboard and plastic containers, considered suitable for such use. In the same way, 36.4\% of households had a first aid kit consisting of medicines and supplies necessary for emergencies. It was also found the place where medicines were kept in the homes visited, obtaining that in $52.5 \%$ of the cases they were in the bedroom, $21.2 \%$ stored them in the room, $13.1 \%$ in the kitchen and 13.1\% kept them in the bathroom, as shown in Fig. 5.

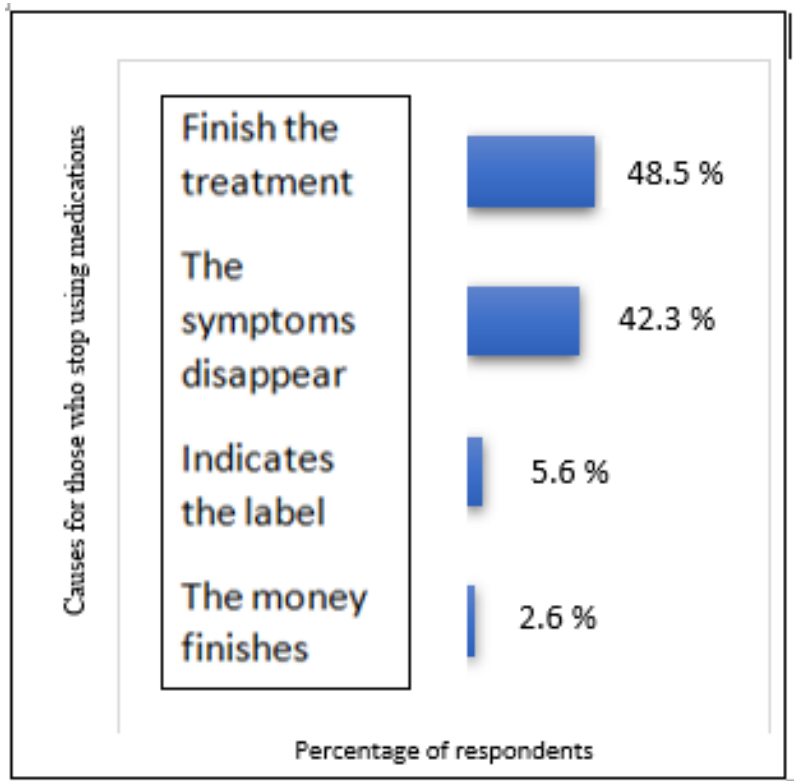

Fig. 4 Causes by which students stop using medications.

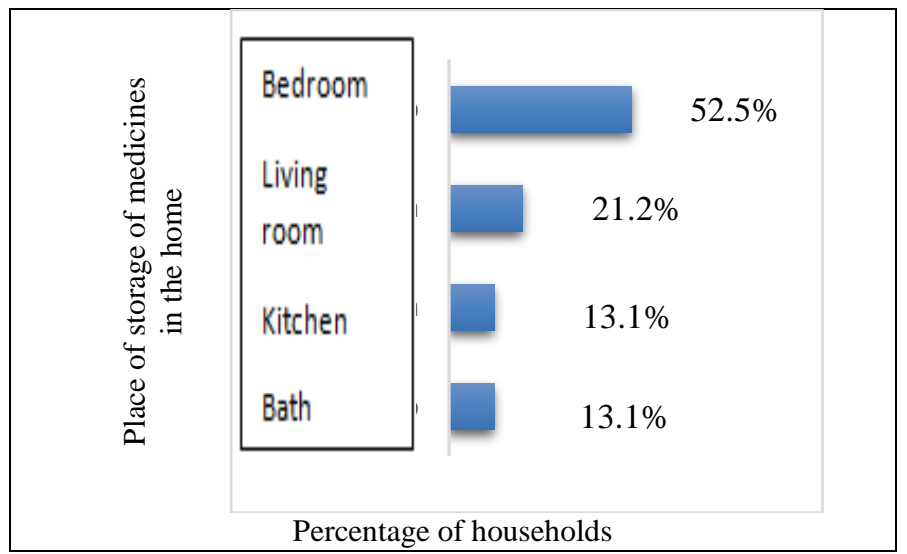

Fig. 5 Storage of medicines according to the place. 


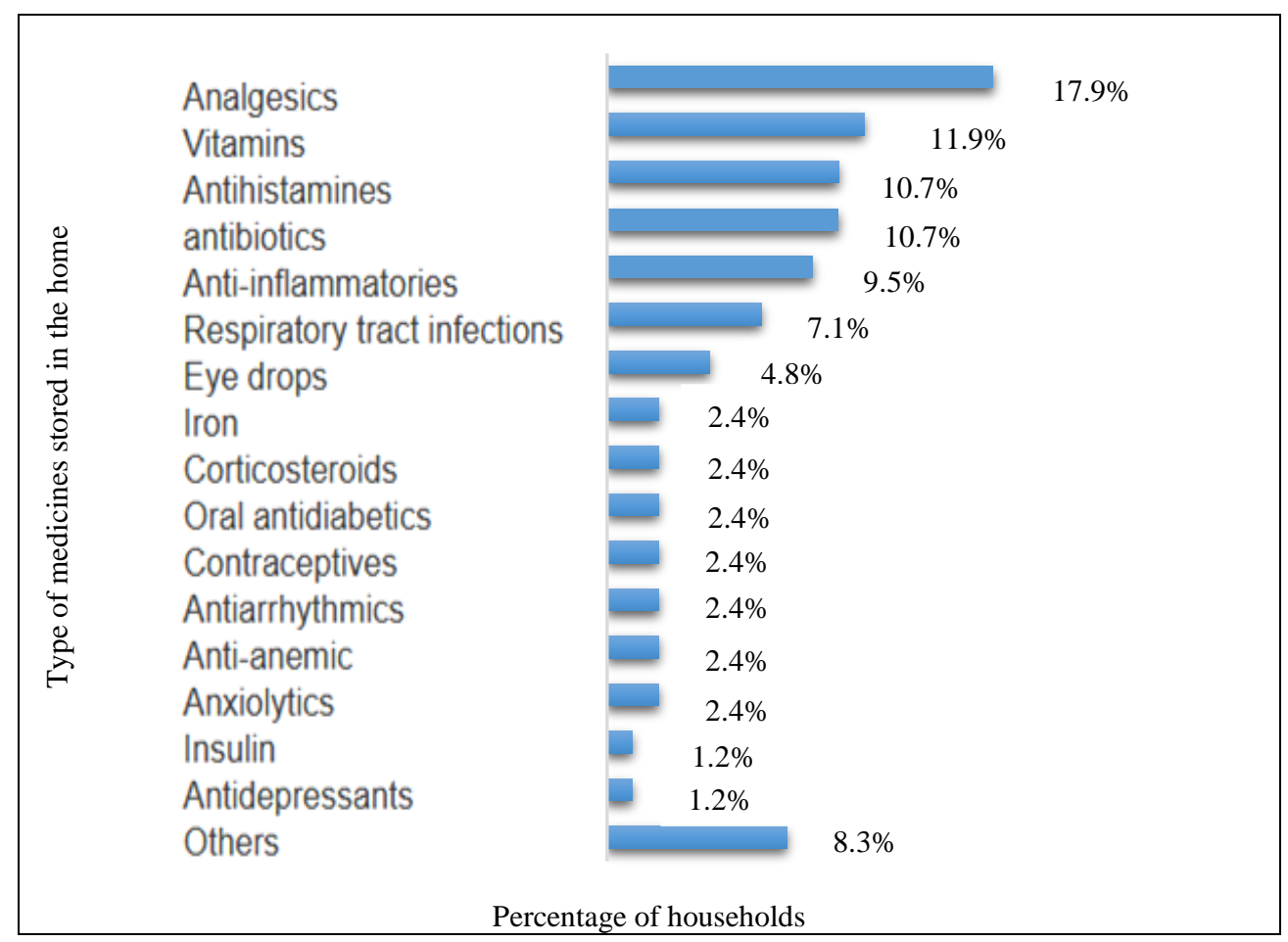

Fig. 6 Type of stored medications.

These results reflect that in an important percentage approximately 26.2\% (bathroom and kitchen), the medicines are stored under conditions of humidity and temperature that threaten the stability of them.

Finally, the types of drugs were determined according to their therapeutic action, found in the homes visited, obtaining the groups that are detailed in Figure 6. These results are comparable with those found in other researches where antibiotics, non-steroidal anti-inflammatory drugs (NSAIDs), antibiotics, anti-flu, vitamins and minerals, contraceptives, among others, are stored in a lesser proportion [19, 20].

\section{Discussion}

In the results which found it was observed that the location and storage conditions of the medicines in the homes of the students were not adequate, although most of them stored them in the dormitory, another important percentage did so in places that allowed direct contact with light, temperature and humidity, factors responsible for physical, chemical and microbiological alterations that threaten the effectiveness and safety of medicines. [21]

This attitude was determined in the students participating in the study, regardless of the area to which the career they were studying belonged. These inadequate habits found through the surveys were confirmed when visiting the homes, where the kitchens and bathrooms constituted, in the same way, places to store the medicines. [22]

Other important results were the data obtained on the causes that led to the storage of medications, as $42.3 \%$ of the respondents stated that they had them stored in their homes, because they had suspended their administration when they felt better.

This aspect is of great relevance, since it constitutes an attitude associated with an irrational use of medicines [23], as it involves self-medication and does not a follow-up of pharmacological therapy indicated by the physician, which often leads, especially in cases of antibiotics, to the administration of a number of compulsorily necessary doses, in order to eliminate the pathogen completely and avoid antimicrobial resistance.

Finally, it was found in the assessment made during 
the home visit that the analgesics correspond to the pharmacological group that was mostly stored in the homes, these data coinciding with those obtained by other researchers where the analgesics are located first $[24,25]$. Another important pharmacological group found in households corresponded to antibiotics, which allows us to presume that these drugs are remnants of treatments that were not completed, which means an irrational use of drugs and a potential antimicrobial resistance. [26, 27]

\section{Conclusions}

A significant percentage of the homes of the students, regardless of the area of knowledge to which the career they belong, stored the medicines in inappropriate places, not following the recommendations of the health institutions that the medicines should be stored in places protected from light, moisture and heat, to safeguard its stability. In the same way, antibiotics were stored, which do not correspond to the composition of the domestic kit and may constitute a potential risk of resistance to antimicrobials. The results reflect that students do not transfer their knowledge about the management of medicines to daily practice, so this analysis performed on their own medicine cabinet should pose challenges based on the implementation of health education strategies that facilitate students especially in careers in the area of health to integrate knowledge and improve their skills on the subject, as they will be the future professionals who should advise their patients on how to properly store medicines at home, to avoid all the negative consequences. It entails not doing it.

\section{References}

[1] World Health Organization (WHO). 2017. Essential Medicines. Essential Medicines According to WHO. Available in: http://www.who.int/topics/essential_medicines/es/. 01

[2] Valentina, B., Florencia, B. M., and Virginia, F. 2015. Qualitative and Quantitative Analysis of Home Botiquínes in Different Cities of Argentina. Concept of Family Medicine Cabinet.

Available

in:
http://pa.bibdigital.uccor.edu.ar/648/1/Tesis\%20BRIZ,\%2 0BRUNA,\%20FERRA.pdf. 24: 271-6. 02

[3] Olivares, G. R. G. 2010. Rational Use of Medicines. Rational Use of Medicines. A Task for Everyone. Available http://web.minsal.cl/portal/url/item/8da19e5eac7b8164e0 4001011e012993.pdf. 03

[4] Bardi, G., Gil, A., Erika, G., et al. 2014. Training Module/Care of Medicines in Primary Health Care. Storage of Medicines in the Home. Available in: http://186.33.221.24/medicamentos//files/MODULO_CU MAPS_SEPTIEMBRE.pdf. 978-950-38-0183-3. 04

[5] Muñóz, F., and Xavier, S. 2008. "Determination of the Reasons and Differences in Self-medication between an Urban and a Rural Parish of the Metropolitan District of Quito.” Thesis on Self-medication in Ecuador. 05

[6] Barreto, L. P. B., and Zenith, P. 2015. Study of the Storage Conditions of Medicines in the Homes of the Pradera District of the Municipality of Pitalillo. Medications in the Home. Available in: http://www.infotegra.com/preview/UNAD.php?url=/bitstr eam/10596/3715/1/59829240.pdf. 06

[7] AIH Nicaragua (International Action for Health). 2009. Irrational Use of Medicines. Factors Associated with the Irrational Use of Drugs. 07

[8] Molina, D. 2014. Classification of Drugs According to Their Therapeutic Action. Classification of Drugs. Available

in: https://prezi.com/des7skye3rlp/clasificacion-de-los-medic amentos-segun-su-accion-farmacolog/. 08

[9] Agujetas, M. 2013. First Aid Kit: An Ally at Home. Storage of Medicines in the Home. Available in http://www.efesalud.com/noticias/botiquin-un-aliado-encasa/. 09

[10] García, F. D., Peña, J. P., and Argüelles, R. F. 2004. The Expiration of Medicines: Justification of a Doubt. Drug Expiration Date. Available in: http://www.bvs.sld.cu/revistas/far/vol38_3_04/far10304.h tm. 10

[11] Ministry of Public Health and Social Assistance of the Republic of El Salvador. 2009. Essential Medicines Classification of Medicines. Available in: http://www.who.int/selection_medicines/country_lists/SL V_Lista_2010.pdf. 11

[12] Al Nono, M. M. 2015. Self-medication in Emergency Patients of a Primary Care Center. Self-medication Doctoral Thesis. Available in: http://roderic.uv.es/bitstream/handle/10550/49902/Tesis \%20V\%2028.pdf?sequence $=1.12$

[13] Magazine: El Comercio. 2013. "Ricardo Amán '50\% of the Urban Population Self-medicates in Ecuador'.” News about Self-medication in Ecuador. Available in: 
http://www.elcomercio.com/tendencias/ricardo-aman-50poblacion-urbana.html. 13

[14] Ministry of Public Health of Ecuador. 2014. National Table of Basic Drugs and Therapeutic Registry. 9th Edition. Available in: http://www.conasa.gob.ec/phocadownload/cnmb9na/Cua dro_Nacional_de_Medicamentos_Basicos_9na_Revision. pdf. 14

[15] Arias, J. L., et. al. 2009. The Future Pharmacist and the Family Kit: Learning How to Carry Out Health Education. Family Firstaid Kit. 15

[16] Kregar, G., and Filinger, E. 2005. "What Is Understood by Self-medication?” Acta Farm. Bonaerense 24 (1): 130-3. Available in: http://www.latamjpharm.org/trabajos/24/1/LAJOP_24_1_ 6_2_5ROG2AU4L2.pdf. 16

[17] Solà, M., et al. 2016. Analysis of Domestic Kits: A Significant Learning Experience for Nursing Students. Florianópolis: Scielo. ISSN 1980-265X. 17

[18] González, J., Orero, A., and Prieto, J. 2006. Storage of Antibiotics in Spanish Homes. Antibiotics in Spain. Available http://seq.es/seq/0214-3429/19/3/Original_J_Gonzalez.pd f. 18

[19] De Pablo, M. M. 2011. Self-medication in the University Culture. Available in: file://C:/Users/USUARIO/Downloads/Dialnet-LaAutom edicacionEnLaCulturaUniversitaria-3897818\%20(2).pdf. 19

[20] World Health Organization (WHO). 2002. Promotion of the Rational Use of Medicines: Central Components. Rational Use of Medicines. Available in: http://apps.who.int/medicinedocs/pdf/s4874s/s4874s.pdf.
20

[21] EFE: Health. 2012. WHO, Stop Self-medication with Antibiotics. Resistance to Bacteria. Available in: http://www.efesalud.com/noticias/oms-stop-a-la-automed icacion-con-antibioticos/. 21

[22] Hernández, E. B., et. al. 2004. Health Education: The First-Aid Kit. Health Education. Available in: http://www.giaf-ugr.org/docenc/master-int.html. 22

[23] Ortega, M. A. M. 2010. Factors Related to Self-medication in Nursing Students of the Faculty of Health Sciences of the Universidad Técnica del Norte. Factors Related to Self-medication. Available in: http://repositorio.utn.edu.ec/bitstream/123456789/696/1/0 6\%20ENF\%20427\%20ART\%C3\%8DCULO\%20CIENT \%C3\%8DFICO.pdf. 23

[24] Ramos, G., and Collaborator. 2010. Rational Use of Medicines. Rational Use of Medicines. A Task for Everyone. Available in: http://web.minsal.cl/portal/url/item/8da19e5eac7b8164e0 4001011e012993.pdf. 24

[25] Texas Department of Insurance. 2007. Training in Five Minutes. Training on Family Kit. 25

[26] Castronuovo, C., Chiclana, F., Giosso, L., Pensa, G., Prario, M., Rebollo, V., Bustos, N., Talevi, A., and Muñoz, S. 2007. "Self-medication in Students of the National University of La Plata.” Lat. Am. J. Pharm. 26 (6): 937-44. Available in http://www.latamjpharm.org/trabajos/26/6/LAJOP_26_6_ 22_0AKQ7SJXN3.pdf. 26

[27] Bartolo, F. P., Rojas, P., and Gadicke, P. 2008. "Evaluation of the Impact of a Health Education Program to Prevent Zoonotic Diseases.” Theoria 17 (1): 61-9. Available in: http://www.ubiobio.cl/theoria/v/v17-1/6.pdf. 27 